\title{
Recent Update of Gastrointestinal Endoscope Reprocessing
}

\author{
Kyong Hee Hong and Yun Jeong Lim \\ Department of Internal Medicine, Dongguk University Ilsan Hospital, Dongguk University College of Medicine, Goyang, Korea
}

\begin{abstract}
As infection-related issues have become one of the most important concerns in endoscopy centers, proper reprocessing of endoscopes has attracted great interest. Compliance with established guidelines for reprocessing is critical to prevent pathogen transmission. However, hospital compliance with guidelines has not been satisfactory. To increase compliance, efforts have focused on developing new and more innovative disinfectants and an automated endoscope reprocessor. Reprocessing must be performed by appropriately trained personnel and regular monitoring of reprocessing is essential for quality assurance to improve compliance.
\end{abstract}

Key Words: Endoscopy, gastrointestinal; Reprocessing, compliance

\section{INTRODUCTION}

Gastrointestinal (GI) endoscopy is an important method for diagnosing and treating numerous medical disorders. Endoscopes are complex and reusable devices. Understanding infection control in the context of endoscopy is important in reducing the transmission of infection. The reported frequency of transmission of infection during GI endoscopy is extremely low; however, the actual prevalence of infection transmission might be higher. ${ }^{1}$ Still, little data exists about the absolute risk of endoscopy-mediated transmission of infection from patient to patient. It is difficult to estimate the causal relationship between endoscopy and pathogen transmission for several reasons, such as long latent period, subclinical symptoms, and unrecognized association of infection with prior endoscopy. There might also be unrecognized infections.

Proper endoscope reprocessing is imperative to prevent transmission of infections during GI endoscopy. In 1978, the Association for Practitioners in Infection Control in America proposed a guideline regarding endoscope disinfection and cleaning for infection control. In 2011, 11 professional orga-

Received: March 24, 2013 Revised: March 26, 2013

Accepted: March 26, 2013

Correspondence: Yun Jeong Lim

Department of Internal Medicine, Dongguk University Ilsan Hospital, Dongguk University College of Medicine, 27 Dongguk-ro, Ilsandong-gu, Goyang 410773, Korea

Tel: +82-31-961-7133, Fax: +82-31-961-9339, E-mail: limyj@dongguk.ac.kr

(c) This is an Open Access article distributed under the terms of the Creative Commons Attribution Non-Commercial License (http://creativecommons.org/ licenses/by-nc/3.0) which permits unrestricted non-commercial use, distribution, and reproduction in any medium, provided the original work is properly cited. nizations including American Society for Gastrointestinal Endoscopy documented evidence-based guidelines for reprocessing GI endoscopes. ${ }^{2}$ Endoscope reprocessing methods developed in the United States and other countries are similar and are the minimum requirements for prevention from transmission of infection. However, their complexity can make compliance difficult, especially in the hospital setting. Many efforts to manage these problems have included the development of better disinfectants and automated endoscope reprocessor (AER) with the emphasis on personnel education, regular monitoring of the reprocessing, and quality assurance.

\section{ENDOSCOPE REPROCESSING PROTOCOL}

The 2011 American Multisociety Guideline, the 2011 World Gastroenterology Organisation global guideline, and the 2012 Korean guideline on the reprocessing of GI endoscopes, ${ }^{2-4}$ all focus on seven steps: precleaning, cleaning, rinsing, disinfection, rinsing, drying, and storage.

After the endoscopy use, precleaning should be done, removing visible debris by wiping the exterior of the endoscope with a detergent solution and aspiration of the bulk of the solution through the air/water and biopsy channels. Next, pressure/leak testing checks the integrity of all channels. This step is done beforehand as a means of avoiding expensive repairs later. Cleaning involves the disconnection and disassembly of all of the available endoscope components and the total immersion of the endoscope and its components in an adequate detergent or soap in accordance with manufacturer's instruc- 
tions. Flushing and brushing of all available channels are done to remove all organic material and other residues. Cleaning of the external surfaces of the endoscope and components is done using a soft cloth, sponge, or brushes. The enzymatic detergents are discarded after one-time use. Disinfection (manually or using an automatic reprocessor) is the next step. This step involves immersion of the endoscope and valves in a proven high-level disinfectant solution for a minimum contact times and at an appropriate temperature. In this stage, all channels are irrigated by syringe to avoid dead spaces and the disinfection solution is removed by flushing with air before rinsing. Manufacturer's recommendations are followed. Following disinfection, the endoscope is rinsed and all channels are flushed using sterile and filtered water or tap water to remove the disinfectant solution. The rinse is discarded after the one-time use. For the final drying step before storage, the channels are flushed with $70 \%$ to $90 \%$ ethyl or isopropyl alcohol and dried using forced air to reduce the risk of remaining pathogens, as well as the possibility of recontamination of the endoscope by waterborne microorganisms. ${ }^{2-4}$

The guidelines are intended to be educational, providing information to endoscopists to help assist in patient care. The guidelines should not be considered as an established standard of care or as a recommendation, requirement, or prohibition of any particular treatment.

\section{TRANSMISSION OF INFECTIONS}

The incidence of exogenous infections, linked to contaminated endoscopes is very low, with an estimated frequency of 1 in every 1.8 million procedures. ${ }^{5}$ The involved pathogens include bacteria, viruses, and protozoa (Table 1). ${ }^{1,6,7}$ Bacteria associated with outbreaks related to endoscope include Pseudomonas aeruginosa, Salmonella spp., Helicobacter pylori, Serratia marcescens, Enterobacter cloacae, Klebsiella spp., Mycobacterium fortuitum, Clostridium difficile, and Flavobacterium spp. Viruses include hepatitis B virus and hepatitis C virus. Parasites include Strongyloides stercoralis and Trichosporon spp. While documented reported cases in domestic hospitals are rare, there have been many reported cases in hospitals abroad.

Most of the outbreaks have involved waterborne organisms. P. aeruginosa, an opportunistic bacterium found widely in the environment, is the most commonly reported organism due to its predilection for moist environments. ${ }^{1}$ P. aeruginosa endoscope contaminations are associated with three major

Table 1. Reported Pathogen Transmission

\begin{tabular}{|c|c|c|c|}
\hline Organism & $\begin{array}{l}\text { No. of reported } \\
\text { cases }\end{array}$ & Years of episodes & Reason for failure \\
\hline \multicolumn{4}{|l|}{ Bacteria } \\
\hline Pseudomonas aeruginosa & 216 & 1974-2005 & $\begin{array}{l}\text { Inadequate cleaning } \\
\text { Inadequate disinfectant } \\
\text { AER or the water supply with its predilection } \\
\text { for a moist environment } \\
\text { Failure to disinfect the elevator channel } \\
\text { of duodenosope } \\
\text { Failure to completely dry channels of the endoscope }\end{array}$ \\
\hline Salmonella & 48 & $\begin{array}{l}\text { 1976-1987, } \\
\text { no reported case } \\
\quad \text { since } 1988\end{array}$ & $\begin{array}{l}\text { Failure to mechanically clean the internal instrument } \\
\text { channel } \\
\text { Inadequate disinfectant } \\
\text { Inadequate disinfectant time }\end{array}$ \\
\hline Helicobacter pylori & 12 & $1988-2000$ & Suboptimal cleaning and disinfection \\
\hline $\begin{array}{l}\text { Enterobacteriacea } \\
\text { including E. coli, Klebsiella, } \\
\text { Enterobacter, and Serratiamarcescens }\end{array}$ & 5 & 1975-1995 & Flaws in the cleaning and disinfection process \\
\hline \multicolumn{4}{|l|}{ Viruses } \\
\hline Hepatitis $\mathrm{C}$ virus & 8 & 1993-2005 & $\begin{array}{l}\text { Contamination of syringe or multi-dose vials } \\
\text { Inadequate disinfection }\end{array}$ \\
\hline Hepatitis B virus & 5 & 1975-1999 & Inadequate disinfection \\
\hline \multicolumn{4}{|l|}{ Parasites } \\
\hline Strongyloides & 1 & 1976 & Unknown \\
\hline
\end{tabular}

AER, automated endoscope reprocessor. 
factors: colonization of the AER or the water supply to the endoscope, failure to disinfect the elevator channel of the duodenoscope, and, most importantly, failure to adequately dry any channels of the endoscope with $70 \%$ alcohol solution and forced air. $^{1}$

Acute viral infections like those caused by hepatitis B and hepatitis $\mathrm{C}$ viruses are usually asymptomatic and can have a long period of incubation. This can hamper the determination of a causal relationship between endoscopy and viral transmission. ${ }^{8}$ Transmission of hepatitis $\mathrm{C}$ virus during endoscopy may be caused by improper reprocessing, inadequate aseptic technique, and improper administration of intravenous medications. ${ }^{8}$ The manner of hepatitis B transmission during GI endoscopy is not well documented, although a few case reports have implicated inadequate endoscopy reprocessing. ${ }^{8}$

\section{DISINFECTANT-INDUCED GI INJURY}

Chemical colitis occurs rarely, by the accidental contamination of endoscopes with disinfectants, in particular glutaraldehyde and hydrogen peroxide. ${ }^{9,10}$ Glutaraldehyde directly injures crypt epithelium and hydrogen peroxide compromises mucosal stroma, which can cause tissue necrosis. ${ }^{11}$ Patients may present with bloody diarrhea, cramping, and fever within 12 to 48 hours after colonoscopy. ${ }^{11}$ A study of 12 patients with pseudolipomatosis that appeared after hydrogen peroxide was introduced as an endoscope disinfectant, concluded that insufficient rinsing of the air channel, which led to the release of residual hydrogen peroxide from the channel, was the probable cause of the pseudolipomatosis, rather than mechanical traumatic injury or intraluminal air pressure during colonoscopy. ${ }^{12}$ These examples highlight the crucial importance of completing all steps of endoscopy reprocessing, including diligent rinsing, according to the established guideline, to minimize exposure to residual disinfectant.

\section{COMPLIANCE WITH ESTABLISHED GUIDELINES}

Consistency in currently recommended reprocessing protocols for endoscopes, specifically cleaning, followed by at least high-level disinfection and drying, may provide a sufficient safety margin to prevent endoscope from transmitting microorganisms, as most reported cases were associated with reprocessing lapse. ${ }^{1,6,8}$ However, the established guidelines are complex and there exist many difficulties within current hospital circumstances.

There have been many national surveys in cleaning and disinfection practice. Soares et al. ${ }^{13}$ reported the assessment of reprocessing practice in 25 endoscopy units of Portuguese hos- pitals. A precleaning was performed in 22 (88\%) units, while the endoscopic materials was transported to reprocessing room in a closed recipient in 11 (44\%) units. Rinsing between cleaning and disinfection was performed in 22 (88\%) units. The endoscopes were systematically disinfected before each session in 12 (48\%) units. Proper drying was performed in 21 (84\%) units while this was performed only occasionally in four $(16 \%)$ units. Endoscopes were stored in ventilated cabinets in 22 (88\%) units or in a closed box in the remaining units. ${ }^{13}$ The same study examined reprocessing of endoscopic accessories. Disposable papillotomes, biopsy forceps, and polypectomy snares were used in nine (36\%), six (24\%), and 14 (56\%) units, respectively, and were reused in three (12\%), two (8\%), and three (12\%) units, respectively. ${ }^{13}$

Ofstead et al. ${ }^{14}$ reported a prospective study on the impact of human factors and automation regarding endoscope reprocessing. The study was conducted in diverse geographic regions in the United States from October 2008 through April 2009. The author presented data regarding the completion of the required steps during manual cleaning with high-level disinfection reprocessing. Sixty-nine units were tested. Seventyseven percent of the units performed leak test in clear water, $100 \%$ were completely disassembled, $45 \%$ had all endoscope channels and components brushed, $99 \%$ of the entire units were completely immersed in detergent, $99 \%$ had complete immersion of the components in detergent, 99\% had endoscopes flushed with detergent, $96 \%$ had endoscope rinsed with water, $84 \%$ of the units were purged with air, $100 \%$ were loaded and the automated cycle for high-level disinfection was completed, $86 \%$ of the units were flushed with alcohol, $45 \%$ had endoscopes dried by forced air, and $90 \%$ of the units had their external surfaces wiped down before being hung to dry. ${ }^{14}$

Compliance with reprocessing guidelines documented in many countries varies widely, ranging from $0 \%$ to $96.5 \%$. One study surveyed members of the Society of Gastroenterology Nurses and Associates and reported compliance with existing guidelines ranged from $67 \%$ to $93 \%{ }^{15}$ Kaczmarek et al. ${ }^{16}$ investigated endoscope reprocessing at 26 health care facilities and found that $24 \%$ of patient-ready endoscope were culture positive. Jackson and Ball ${ }^{17}$ surveyed 19 family practices and internal medicine offices regarding the compliance with reprocessing guidelines. The private hospitals surveyed had a compliance rate of $0 \% .{ }^{17}$ Other reported compliance rates were $79 \%$ in Spain, ${ }^{18} 52 \%$ to $74 \%$ and $90 \%$ in Germany, ${ }^{19}$ and $17.2 \%$ to $96.5 \%$ in Romania. ${ }^{20}$ Table 2 illustrates the compliances of existing guidelines. ${ }^{13,15-24}$

Even though the results of some studies indicated improved reprocessing activity compared with previous surveys, there still remain many problems to be improved. To fulfill the complete reprocessing, improvements in endoscopy equipment, 
Table 2. Compliance of Established Guidelines

\begin{tabular}{llcc}
\hline Investigator (reported time in year) & \multicolumn{1}{c}{ Object } & Compliance, \% & Culture positive, \% \\
\hline Gorse et al. $(1991)^{15}$ & 2,030 Members of SGNA in USA & $67-93$ & - \\
Kaczmarek et al. $(1992)^{16}$ & 26 Health care facilities in USA & - & 24 \\
Jackson et al. $(1997)^{17}$ & 19 Family practice and internal medicine offices in USA & 0 & - \\
Brullet et al. $(2001)^{18}$ & 144 Centers in Spain & 79 & - \\
Moses et al. $(2004)^{21}$ & 230 Members of SGNA in USA & $52-74$ (in 2003) \\
Heudorf et al. $(2006)^{19}$ & 23 Private practices in Germany & 90 (in 2004) \\
Frățilă et al. $(2006)^{20}$ & 29 Centers in Romania & $17.2-96.5$ \\
Schaefer et al. $(2010)^{22}$ & 67 Ambulatory surgical centers in USA & 28.4 & - \\
Barbosa et al. $(2010)^{23}$ & 60 Endoscopes in 20 medical services in Brazil & $10-35$ & - \\
Zhang et al. $(2011)^{24}$ & 122 Endoscopy units in China & 29.5 & - \\
Soares et al. $(2011)^{13}$ & 25 Units in Portugal & $48-88$ & - \\
\hline
\end{tabular}

SGNA, the Society of Gastroenterology Nurses and Associates.

full awareness of the importance of compliance with the current guidelines, and quality assurance should be strongly encouraged. Moreover, each individual involved in reprocessing needs to be trained properly with initial and annual competency testing. ${ }^{25}$

\section{DISINFECTANTS}

The ideal disinfectant needs to be effective against a wide range of organisms including blood-borne viruses and prion proteins; compatible with endoscopes, accessories, and endoscope reprocessor; nonirritating and safe for users; and environmentally friendly for disposal. ${ }^{3,26}$

Of the many disinfectants that are available, six have been approved by the United States Food and Drug Administration (USFDA) and Korea Food and Drug Administration (KFDA): glutaraldehyde, orthophthalaldehyde, peracetic acid, hydrogen peroxide, electrolyzed acid water, and peracetic acid/hydrogen peroxide blend..$^{27,28}$

Others not approved for endoscope reprocessing by the USFDA and KFDA include chloride dioxide, ozonated water, peroxygen compound, and quarternary ammonium.

Chloride dioxide is highly effective as a disinfectant. Sporicidal activity is assured in 10 minutes and bactericidal and virucidal activity in 5 minutes with manufacturers' prescribed condition. Sporicial activity is maintained for 7 to 14 days if it is stored in sealed containers with minimal empty space. However, chlorine dioxide emits strong fumes during preparation and use, causing respiratory irritation, and enclosed or exhaust ventilated facilities are required. Moreover, it may damage instruments and processor components, and compatibility tests need to be carried out. ${ }^{29}$

Ozonated water used to disinfect food and wastewater has strong acidity and exhibits microbicidal activities against bacteria and fungi. It can be prepared cheaply using salt and tap water and is safe for humans. But its antimicrobicial activity as a suitable disinfectant for GI endoscopes has not been validated. ${ }^{30}$

Peroxygen compound is effective against most vegetative bacteria and viruses. However, it is less effective against mycobacteria and enteroviruses compared with glutaraldehyde and may affect the components of endoscopes and processing equipment. $^{29}$

Quarternary ammonium compounds are not recommended as disinfectants for GI endoscopes due to deficiencies in their spectrum of antimicrobial activity. ${ }^{29}$ However, with the demand for making new and more innovative disinfectant and/or combining existing disinfectants to enhance safety and improve efficacy, there have been some studies assessing new products. Kim et al. ${ }^{31}$ reported assessment of the new product, a combination of polyhexamethylenebiguanide and alkyldimethylbenzylammonium chiolride, both of which are quarternary ammonium compounds with antimicrobial activity. The study concluded that it could be a good alternative even though more studies may be required.

\section{AER}

AERs are designed to replace some manual reprocessing steps or manual disinfection by passive immersion in liquid chemical germicides and manual flushing of channels with liquid chemical germicides, which has a similar efficacy for high-level disinfection. ${ }^{32}$ The automated system reduce exposure of users to hazardous reprocessing chemicals such as disinfectants.

Advanced and upgraded AERs are being developed in- 
cluding the USFDA approved EVOTCH Endoscope Cleaner and Reprocessor (ECR). EVOTCH eliminates manual precleaning of the endoscope prior to automated high-level disinfection processing. ${ }^{33}$ Evaluation of the EVOTCH system documented the attainment or surpassing of cleaning endpoints for protein, hemoglobin, and bioburden residuals for $98.8 \%$ of the surfaces and $99.7 \%$ of lumens in the clinical study. It also demonstrated the attainment or surpassing of cleaning endpoints for protein and bioburden residuals for $100 \%$ of endoscopes and bronchoscopes in the simulated-use study. ${ }^{34}$ Assessment of the cost-efficiency of the ECR approaches in an actual practice setting demonstrated a significantly shorter time of endoscope reprocessing and reduced cost compared with manual cleaning followed by automated reprocessing. The value of the labor time saved with ECR offset the additional cost of consumables. ${ }^{35}$

\section{PERSONNEL TRAINING AND QUALITY ASSURANCE}

All health care personnel in the endoscopy unit should be trained in standard infection prevention and control recommendations including those to protect both patients and health care workers. Protective equipments should be available for protection against exposure to chemicals or potentially infectious materials. ${ }^{3,32}$

Personnel assigned to reprocess endoscopes should receive device-specific reprocessing instructions to carry out proper cleaning and high-level disinfection or sterilization. Competency testing of personnel that reprocess endoscopes should be done and documented on a regular basis.

It is necessary to monitor efficacy of the disinfection at regular intervals for quality assurance. All endoscope channels need to be checked for contamination. The manufactures' instructions should be followed regarding the intervals, media, and culture. ${ }^{3}$

\section{MICROBIOLOGICAL SURVEILLANCE TEST}

Microbiological surveillance is an essential tool for evaluating the quality of reprocessing procedures with regular quality control in GI endoscope. However the frequency and the method of microbiological testing for endoscopes and AER remain contentious as does the correlation with nosocomial transmission. In the United States, routine microbiological culturing is not recommended and is preferred only if nosocomial clusters are suspected. ${ }^{2,36}$ Australian guidelines require

Table 3. Microbiological Surveillance Test

\begin{tabular}{|c|c|c|c|}
\hline $\begin{array}{l}\text { Guidelines or investigators } \\
\text { (reported time in year) }\end{array}$ & Method & Sampling site & Frequency \\
\hline$\overline{\mathrm{APIC}}(2000)^{36}$ & Rinse samples culture & $\begin{array}{l}\text { Suction/biopsy, air/water, elevator, } \\
\text { and carbon dioxide channels }\end{array}$ & Routine test not recommended \\
\hline GESA $(2003)^{37}$ & $\begin{array}{l}\text { Rinse samples culture for channels } \\
\text { Sample from manufactures' guideline } \\
\text { culture for AER }\end{array}$ & $\begin{array}{l}\text { All channels } \\
\text { AER }\end{array}$ & Every 4 weeks \\
\hline German $(2004)^{39}$ & Rinse samples culture & All channels & \\
\hline ESGE-ESGENA $(2008)^{40}$ & $\begin{array}{l}\text { Rinse samples culture for channels } \\
\text { and water bottle } \\
\text { Swab culture from outer surface }\end{array}$ & $\begin{array}{l}\text { All channels } \\
\text { The outer surfaces } \\
\text { The connected water bottle }\end{array}$ & No longer than 3 months \\
\hline BSG $(2008)^{26}$ & Culture for atypical mycobacteria & AER & Annual testing \\
\hline Canada $(2010)^{41}$ & Rinse sample culture & Suction/biopsy and air/water channel & Routine test not recommended \\
\hline ASGE-SHEA $(2011)^{2}$ & & & Routine test not recommended \\
\hline Gillespie et al. $(2007)^{38}$ & Rinse sample culture & $\begin{array}{l}\text { Suction/biopsy and air/water channel } \\
\text { AER channel }\end{array}$ & Annually \\
\hline Chiu et al. $(2010)^{42}$ & Rinse sample culture & Internal channel & \\
\hline Alfa et al. $(2012)^{43}$ & Rapid use scope test & Suction/biopsy channel & \\
\hline Chiu et al. $(2012)^{44}$ & Rinse sample culture & Biopsy channel & \\
\hline Lu et al. $(2012)^{45}$ & Swab culture & AER & \\
\hline
\end{tabular}

APIC, The Association for Professionals in Infection Control and Epidemiology; GESA, Gastroenterological Society of Australia; AER, automated endoscope reprocessor; ESGE-ESGENA, European Society of Gastrointestinal Endoscopy and the European Society of Gastroenterology and Endoscopy Nurses and Associates; BSG, British Society of Gastroenterology; ASGE-SHEA, American Society for Gastrointestinal Endoscopy and the Society for Healthcare Epidemiology of America. 
all AERs and processed endoscopes to be monitored every 4 weeks. ${ }^{37}$ Spanish and New Zealand guidelines recommend periodic culturing only from endoscopes, while Australian guidelines suggest culturing samples from both of AERs and endoscopes..$^{38}$ Table 3 summarizes information from the available guidelines or reports related to microbiological monitoring. ${ }^{2,36-45}$

Microbiological surveillance is an instrument for detecting weakness and deficiencies in reprocessing process, and so is vital for preventing pathogen transmission through endoscopy.

\section{UNRESOLVED ISSUES}

A variety of issues related to endoscope reprocessing remains unresolved. First, shelf life, the interval of storage after which endoscopes need to be reprocessed before use is unclear. Even though reuse within 10 to 14 days appears to be safe, the maximal duration for use of reprocessed endoscopes remains unclear. ${ }^{2}$ Osborne et al ${ }^{46}$ reported a prospective study inspecting the safe shelf life of endoscopes. The study suggested that if reprocessing process is appropriately done according to the established guidelines, endoscopes remain free from pathogenic organisms for at least 120 hours between reprocessing. This could be applicable to high-turnover facilities where the mean time between reprocessing is less than 48 hours, as well as to emergency cases.

Secondly, the proper frequencies for replacement of clean water bottles, tubing for insufflation of air and lens wash water, waste vacuum canisters and suction tubing have not been determined. Concern relates to the possibility of backflow from a soiled endoscope against the direction of forced fluid and air passage into the clean air/water source and, in the other, from contaminated tubing and collection chamber against a vacuum into clean instruments used for subsequent patients. The safety and potential risk per procedure versus per-day exchange of these attachments need to be investigated. ${ }^{2}$

Lastly, there are no established data regarding endoscope durability and longevity. The potential for reduced function or reduced ability to reach high level disinfection after a certain number of years or procedures need to be investigated. ${ }^{2}$

\section{CONCLUSIONS}

As endoscopes are reusable apparatuses, proper endoscope reprocessing is essential to prevent transmission of infection during GI endoscopy. As compliance with established guidelines for the reprocessing has been not satisfactory, outbreaks of infection related to lapses in endoscope reprocessing have taken place. Therefore, there have been many efforts to devel- op more efficient and safe disinfectants as well as more convenient and labor saving endoscope reprocessors. In addition, it is important to monitor the efficacy of the disinfection at regular intervals. Trained personnel should perform the decontamination of endoscopes in dedicated rooms.

\section{Conflicts of Interest}

The authors have no financial conflicts of interest.

\section{REFERENCES}

1. Nelson DB, Muscarella LF. Current issues in endoscope reprocessing and infection control during gastrointestinal endoscopy. World J Gastroenterol 2006;12:3953-3964.

2. ASGE Quality Assurance In Endoscopy Committee, Petersen BT, Chennat J, et al. Multisociety guideline on reprocessing flexible gastrointestinal endoscopes: 2011. Gastrointest Endosc 2011;73:1075-1084.

3. World Gastroenterology Organisation, World Endoscopy Organization Global Guidelines. Endoscope disinfection: a resource-sensitive approach [Internet]. Munich: World Gastroenterology Organisation; c2005 [updated $2011 \mathrm{Feb} 1$; cited 2003 Mar 10]. Available from: http:// www.worldendo.org/assets/downloads/pdf/guidelines/wgo_weo_endoscope_disinfection.pdf.

4. The Korean Society of Gastrointestinal Endoscopy Disinfection Management Committee. Guidebook for Cleaning and Disinfecting Gastrointestinal Endoscopes. 1st ed. Seoul: Medbook;2012. p.93.

5. Spach DH, Silverstein FE, Stamm WE. Transmission of infection by gastrointestinal endoscopy and bronchoscopy. Ann Intern Med 1993; 118:117-128.

6. Lisgaris MV. The occurrence and prevention of infections associated with gastrointestinal endoscopy. Curr Infect Dis Rep 2003;5:108-113.

7. ASGE Standards of Practice Committee, Banerjee S, Shen B, et al. Infection control during GI endoscopy. Gastrointest Endosc 2008;67: 781-790.

8. Wu H, Shen B. Health care-associated transmission of hepatitis B and C viruses in endoscopy units. Clin Liver Dis 2010;14:61-68.

9. Cho SK, Kim YK, Lee YR, et al. A case of hydrogen peroxide induced colitis. Korean J Gastrointest Endosc 1999;19:659-666.

10. West AB, Kuan SF, Bennick M, Lagarde S. Glutaraldehyde colitis following endoscopy: clinical and pathological features and investigation of an outbreak. Gastroenterology 1995;108:1250-1255.

11. Ryan CK, Potter GD. Disinfectant colitis. Rinse as well as you wash. J Clin Gastroenterol 1995;21:6-9.

12. Kim SJ, Baek IH. Colonic mucosal pseudolipomatosis: disinfectant colitis? Gastroenterol Nurs 2012;35:208-213.

13. Soares JB, Gonçalves R, Banhudo A, Pedrosa J. Reprocessing practice in digestive endoscopy units of district hospitals: results of a Portuguese National Survey. Eur J Gastroenterol Hepatol 2011;23:1064-1068.

14. Ofstead CL, Wetzler HP, Snyder AK, Horton RA. Endoscope reprocessing methods: a prospective study on the impact of human factors and automation. Gastroenterol Nurs 2010;33:304-311.

15. Gorse GJ, Messner RL. Infection control practices in gastrointestinal endoscopy in the United States: a national survey. Infect Control Hosp Epidemiol 1991;12:289-296.

16. Kaczmarek RG, Moore RM Jr, McCrohan J, et al. Multi-state investigation of the actual disinfection/sterilization of endoscopes in health care facilities. Am J Med 1992;92:257-261.

17. Jackson FW, Ball MD. Correction of deficiencies in flexible fiberoptic sigmoidoscope cleaning and disinfection technique in family practice and internal medicine offices. Arch Fam Med 1997;6:578-582.

18. Brullet E, Ramirez-Armengol JA, Campo R; Board of the Spanish Association for Digestive Endoscopy. Cleaning and disinfection practices in digestive endoscopy in spain: results of a national survey. Endoscopy 
2001;33:864-868.

19. Heudorf U, Exner M. German guidelines for reprocessing endoscopes and endoscopic accessories: guideline compliance in Frankfurt/Main, Germany. J Hosp Infect 2006;64:69-75.

20. Frățilă O, Tanțău M. Cleaning and disinfection in gastrointestinal endoscopy: current status in Romania. J Gastrointestin Liver Dis 2006;15: 89-93.

21. Moses FM, Lee JS. Current GI endoscope disinfection and QA practices. Dig Dis Sci 2004;49:1791-1797.

22. Schaefer MK, Jhung M, Dahl M, et al. Infection control assessment of ambulatory surgical centers. JAMA 2010;303:2273-2279.

23. Barbosa JM, Souza AC, Tipple AF, Pimenta FC, Leão LS, Silva SR. Endoscope reprocessing using glutaraldehyde in endoscopy services of Goiania, Brazil: a realidade em servicos de endoscopia de Goiania, GO. Arq Gastroenterol 2010;47:219-224.

24. Zhang X, Kong J, Tang P, et al. Current status of cleaning and disinfection for gastrointestinal endoscopy in China: a survey of 122 endoscopy units. Dig Liver Dis 2011;43:305-308.

25. Society of Gastroenterology Nurses and Associates Inc., SGNA Standards: standards of infection control in reprocessing of flexible gastrointestinal endoscopes. Gastroenterol Nurs 2010;33:70-80.

26. British Society of Gastroenterology. BSG guidelines for decontamination of equipment for gastrointestinal endoscopy: report of a working party of the British Society of Gastroenterology Endoscopy Committee [Internet]. London: British Society of Gastroenterology; c2009 [updated 2008 Feb 1; cited 2013 Mar 10]. Available from: http://www.bsg.org. uk/pdf_word_docs/decontamination_2008.pdf.

27. U.S. Food and Drug Administration. FDA-cleared sterilants and high level disinfectants with general claims for processing reusable medical and dental devices: March 2009 [Internet]. Silver Spring: U.S. Food and Drug Administration; 2009 [updated 2009 Apr 26; cited 2013 Mar 10]. Available from: http://www.fda.gov/MedicalDevices/DeviceRegulationandGuidance/ReprocessingofSingle-UseDevices/ucm 133514. htm.

28. Kim HJ. KFDA-cleared disinfectants in gastrointestinal endoscopy. Korean J Gastrointest Endosc 2010;42:50-52.

29. Cleaning and disinfection of equipment for gastrointestinal endoscopy. Report of a Working Party of the British Society of Gastroenterology Endoscopy Committee. Gut 1998;42:585-593.

30. Urata $\mathrm{M}$, Isomoto $\mathrm{H}$, Murase $\mathrm{K}$, et al. Comparison of the microbicidal activities of superoxidized and ozonated water in the disinfection of endoscopes. J Int Med Res 2003;31:299-306.

31. Kim SY, Lee HS, Hyun JJ, et al. Comparison on the efficacy of disinfectants used in automated endoscope reprocessors: PHMB-DBAC versus orthophthalaldehyde. Clin Endosc 2011;44:109-115.

32. ASGE Technology Committee, Desilets D, Kaul V, et al. Automated endoscope reprocessors. Gastrointest Endosc 2010;72:675-680.

33. Food and Drug Administration. 510(k) Summary [Internet]. Silver Spring: Food and Drug Administration; c2008 [updated 2008 Nov 13; cited 2011 Apr 20]. Available from: http://www.accessdata.fda.gov/ cdrh_docs/pdf8/K082392.pdf.

34. Alfa MJ, DeGagne P, Olson N, Fatima I. EVOTECH endoscope cleaner and reprocessor (ECR) simulated-use and clinical-use evaluation of cleaning efficacy. BMC Infect Dis 2010;10:200.

35. Forte L, Shum C. Comparative cost-efficiency of the EVOTECH endoscope cleaner and reprocessor versus manual cleaning plus automated endoscope reprocessing in a real-world Canadian hospital endoscopy setting. BMC Gastroenterol 2011;11:105.

36. Alvarado CJ, Reichelderfer M. APIC guideline for infection prevention and control in flexible endoscopy. Association for Professionals in Infection Control. Am J Infect Control 2000;28:138-155.

37. Cowen AE; Gastroenterological Society of Australia; Gastroenterological Nurses Society of Australia. Infection Control in Endoscopy: Guidelines \& Clinical Update. 2nd ed. Sydney: Gastroenterological Society of Australia; 2003.

38. Gillespie EE, Kotsanas D, Stuart RL. Microbiological monitoring of endoscopes: 5-year review. J Gastroenterol Hepatol 2008;23(7 Pt 1):10691074.

39. Heeg P. Reprocessing endoscopes: national recommendations with a special emphasis on cleaning: the German perspective. J Hosp Infect 2004;56 Suppl 2:S23-S26.

40. Beilenhoff U, Neumann CS, Rey JF, et al. ESGE-ESGENA guideline: cleaning and disinfection in gastrointestinal endoscopy. Endoscopy 2008; 40:939-957.

41. Public Healthy Agency of Canada. Infection prevention and control guideline for flexible gastrointestinal endoscopy and flexible bronchoscopy [Internet]. Ottawa: Public Healthy Agency of Canada; c2011 [updated 2011 Feb 10; cited 2013 Mar 10]. Available from: http://www. phac-aspc.gc.ca/nois-sinp/guide/endo/pdf/endo-eng.pdf.

42. Chiu KW, Fong TV, Wu KL, et al. Surveillance culture of endoscope to monitor the quality of high-level disinfection of gastrointestinal reprocessing. Hepatogastroenterology 2010;57:531-534.

43. Alfa MJ, Olson N, Degagné P, Simner PJ. Development and validation of rapid use scope test strips to determine the efficacy of manual cleaning for flexible endoscope channels. Am J Infect Control 2012;40:860865.

44. Chiu KW, Tsai MC, Wu KL, Chiu YC, Lin MT, Hu TH. Surveillance cultures of samples obtained from biopsy channels and automated endoscope reprocessors after high-level disinfection of gastrointestinal endoscopes. BMC Gastroenterol 2012;12:120.

45. Lu LS, Wu KL, Chiu YC, Lin MT, Hu TH, Chiu KW. Swab culture monitoring of automated endoscope reprocessors after high-level disinfection. World J Gastroenterol 2012;18:1660-1663.

46. Osborne S, Reynolds S, George N, Lindemayer F, Gill A, Chalmers M. Challenging endoscopy reprocessing guidelines: a prospective study investigating the safe shelf life of flexible endoscopes in a tertiary gastroenterology unit. Endoscopy 2007;39:825-830. 